\title{
POSTERIOR REVERSIBLE ENCEPHALOPATHY SYNDROME (PRES) IN A PATIENT WITH SYSTEMIC LUPUS ERYTHEMATOSUS USING CYCLOPHOSPHAMIDE. CASE REPORT
}

Stan Richard Medeiros de Souza ${ }^{1, \star}$, Adriana Cristiane Machado ${ }^{1}$, Elisa Pereira Vicentini ${ }^{1}$, Tamires Guimarães Costa ${ }^{1}$, Estêvão da Costa Santana ${ }^{1}$, Lucas Victória de Oliveira Martin ${ }^{1}$, Renata Ferreira Rosa ${ }^{1}$, Rina Dalva Pereira Neubarth Giorgi ${ }^{1}$, Nafice Costa Araújo ${ }^{1}$

1.Instituto de Assistência Médica ao Servidor Público Estadual, São Paulo (SP), Brazil.

*Corresponding author: stanrichardms@gmail.com

\section{BACKGROUND}

Posterior reversible encephalopathy syndrome (PRES) is described by sudden onset of headache, seizure, systemic arterial hypertension (SAH), altered mental status and transient visual loss, associated with changes that are manifested in brain magnetic resonance imaging (MRI) and computed tomography $(\mathrm{CT})$, such as subcortical, cortical edema and deep lesions, mainly in the occipital and parietal lobes. The most common causes of PRES include SAH, preeclampsia/eclampsia, immunosuppressive or postchemotherapy, autoimmune diseases and infection. In systemic lupus erythematosus (LES), PRES predominates in women and rare in children and adolescents. We will report the case of an adolescent, with SLE in renal activity, which applies PRES after use of cyclophosphamide.

\section{CASE REPORT}

J.P.M.C., 15 years old, male, diagnosed with SLE in January 2020, due to renal impairment, pleural effusion, leukopenia, FAN 1/640 fine dotted pattern, complement consumption and positive anti-Sm. He was admitted to the hospital with acute renal failure, requiring renal replacement therapy. Pulse therapy with methylprednisolone (MP) was started $1 \mathrm{~g} /$ day for 3 days and opted for monthly pulse therapy with cyclophosphamide (CCF) after renal biopsy showing grade IV nephritis. Discharge using prednisone $40 \mathrm{mg} / \mathrm{day}$ and hydroxychloroquine sulfate (HCQ) 400 mg/day, with improvement in renal function. He performed two doses of CCF, the first in January and the second 1 month later. In early March, he developed chickenpox. On March 22, he was readmitted for epileptic illness, requiring orotracheal intubation. On admission, brain CT and cerebrospinal fluid collection were normal. Empirical treatment for viral encephalitis was initiated and opted for pulse therapy with MP and CCF, due to the hypothesis of cerebral vasculitis. He developed hard control SAH, requiring the use of nipride. RM of related products compatible with PRES. The patient evolved with improvement of the hypertensive condition, being discharged with mycophenolate mofetil (MMF) $2 \mathrm{~g} / \mathrm{day}$, prednisone 30 mg/day and HCQ 400 mg/day. Outpatient return with a new MRI that proved to be normal.

\section{CONCLUSION}

The PRES in the case described may be influenced by factors such as kidney disease, SAH, use of CCF and MP. The literature has shown, however, many reports associated with the use of chemotherapy. This diagnosis should be considered in patients with SLE and neurological conditions, in use especially for CCF, due to its potential for reversibility. 